\title{
Characterization of Directional Elastoplastic Properties of Al/Cu Bimetallic Sheet
}

\author{
Robert Uscinowicz
}

\author{
(Submitted May 11, 2018; in revised form November 21, 2018; published online February 13, 2019)
}

\begin{abstract}
The paper presents the results of the study aimed at determining the elastoplastic properties of an $\mathrm{Al} / \mathrm{Cu}$ bimetallic sheet consisting of aluminum and copper layers, which were joined by cold rolling. The values of elasticity coefficients in three orthotropic planes as well as the Kirchhoff modulus, and coefficient of internal friction in the perpendicular direction to the lamination were determined. The subjects of the analysis were also the values of limit stresses, uniform energy of elastic and plastic strain per unit volume, and coefficients of the hardening curve and normal anisotropy. The tests were carried out on bimetallic specimens with varying thicknesses of the copper layer, cut from the $\mathrm{Al} / \mathrm{Cu}$ sheet in the direction of rolling and in the direction perpendicular to it. Two methods of determining the directional values of mechanical parameters were used in the tests, i.e., the uniaxial quasi-static tensile test and the dynamic acoustic resonance method. It was concluded that these methods made it possible to determine directional elastoplastic properties of the $\mathrm{Al} / \mathrm{Cu}$ bimetallic sheet taking into account the variable share of components in the bimetal and the direction of cutting out specimens from cold-rolled sheet.
\end{abstract}

Keywords aluminum-copper bimetal, elastoplastic properties, electronic materials, joining, nondestructive testing, nonferrous metals, tensile test

\section{Introduction}

The design of mechanical structures and processes of plastic forming require the knowledge of elastoplastic properties of deformable material. In the case of structurally homogeneous and isotropic materials, the identification of the mechanical properties by experiment is relatively easy. The tests carried out on modern constructional materials, which are characterized by the heterogeneity of the internal structure and the directional changeability of the physical properties, are problematic. Additional difficulties during the tests are their form and shape, which are usually the results of the previously performed plastic forming. An example of such a structure may be a laminated sheet metal manufactured by joining two or more metal sheets characterized by different physical properties.

There are three basic methods for production of bimetallic sheets. These are methods related to the casting of one or more layers of metal to another liquid or solid layer and technologies using large plastic deformation or non-deforming methods (welding, spraying) where bonding of metal layers takes place with the participation of small values of plastic deformation. On

Robert Uscinowicz, Department of Mechanics and Applied Computer Science, Faculty of Mechanical Engineering, Bialystok University of Technology, Wiejska 45C, 15-351 Białystok, Poland. Contact e-mail: r.uscinowicz@pb.edu.pl. the other hand, Forster et al. (Ref 1) additionally described modern methods of physical and chemical deposition, electrophoresis and others. An overview of the methods of bimetal production can also be found in the works of Smith and Celant (Ref 2), and classification based on the shape of the final product was presented. The most common and cost-effective methods of joining metal sheets from different metals are cold or hot rolling and the explosive method (Ref 3-6).

The problems of deformability of two- and three-layer metals in the form of sheets and plates are frequently described in publications, but most of the papers (Ref 7-10) usually pay attention to technological issues related to the production of bimetals and the evaluation of their quality, without penetrating into the stress-strain relations accompanying the elastoplastic deformation in the joined layers of metals. Processes occurring at the phase separation interface of bimetallic layers are very often analyzed (Ref 11-14). The papers of Semiatin and Piehler (Ref 15), Lee and Kim (Ref 16, 17), Choi et al. (Ref 18) can be mentioned as publications dealing with mechanical aspects of deformations of multilayer metals.

Elements made from $\mathrm{Al} / \mathrm{Cu}$ sheets are widely used in power engineering, electrical engineering or electronics. They are also used in the production of everyday objects such as roof and wall panels, heat exchangers, electrical elements, engraving plates and kitchen appliances with an induction heater (Ref 2, 19).

The aim of this study was to determine the directional values of the parameters describing the selected elastoplastic properties of the $\mathrm{Al} / \mathrm{Cu}$ metal composite in the form of a metal sheet taking into account the varying thicknesses of the copper layer. This involved answering the question of to what extent does the thickness of the copper layer affect the elastoplastic properties in the $\mathrm{Al} / \mathrm{Cu}$ bimetal. The influence of the bimetal sheet-forming process during rolling on the directional mechanical parameters of the $\mathrm{Al} / \mathrm{Cu}$ bimetallic structures was studied and analyzed. It should be emphasized that the application of a thicker copper layer in the $\mathrm{Al} / \mathrm{Cu}$ sheet increases cost and mass. 


\section{Experimental Procedure}

\subsection{Materials and Specimens}

Three types of specimens were used in experimental tests, i.e.,

(a) Flat specimens with a "dog-bone" shape, made from $\mathrm{Al} / \mathrm{Cu}$ bimetal (Fig. 1a),

(b) Bimetallic $\mathrm{Al} / \mathrm{Cu}$ specimens in the shape of rectangular prisms (Fig. 1b),

(c) Aluminum specimens with the shapes and dimensions described in (a) and (b), obtained from bimetallic sheet, but completely devoid of the copper layer.

Specimens were formed from strips with nominal dimensions $200 \times 25 \mathrm{~mm}$, and the final shape was achieved by milling. Strips were cut from a layered aluminum-copper sheet with dimensions of $4 \times 500 \times 1000 \mathrm{~mm}$ in two directions, i.e., in the rolling direction $\left(0^{\circ}\right)$ and the direction perpendicular to it $\left(90^{\circ}\right)$. It should be emphasized that, for each individual bimetallic strip, two specimens of the same thickness, but with a fundamentally different shape (Fig. 1), were cut out at the same time.

The most numerous group of bimetallic $\mathrm{Al} / \mathrm{Cu}$ specimens were machined to reduce the thickness of the copper layer in comparison with the aluminum layer. This involved reducing the thickness of the $\mathrm{Cu}$ layer by approx. $0.6 \mathrm{~mm}$. Thickness measurement of individual layers in bimetallic and aluminum specimens was performed by means of graphical analysis methods by registering their macroscopic images. The share of copper in $\mathrm{Al} / \mathrm{Cu}$ bimetallic specimens, as a percentage, amounted to, respectively, $0 \%, 25 \%, 40 \%, 45 \%, 50 \%$.

The main components of the $\mathrm{Al} / \mathrm{Cu}$ bimetal were $\mathrm{M} 1 \mathrm{E}$ grade copper and A1-grade aluminum. The mean share of components in the as-delivered (unprocessed) $\mathrm{Al} / \mathrm{Cu}$ bimetal, as a percentage, amounted to $\mathrm{Cu}-49 \%$ and $\mathrm{Al}-51 \%$. The bimetallic sheet was obtained by cold rolling an aluminum (A1) sheet together with a copper (M1E) sheet leading to adhesion. Before joining, the aluminum and copper sheets were annealed (recrystallized), and their surfaces were scratch-brushed, in order to remove oxide layer. The total deformed reduction of thickness was about $40 \%$, and the rolling process was in a few passes. The chemical composition of the copper and aluminum sheets, i.e., the bimetal's main components, is presented in Tables 1 and 2. Basic elastoplastic properties of the aluminum (A1) sheet and copper (M1E) sheet, the components of the bimetal $\mathrm{Al} / \mathrm{Cu}$, after annealing and before joining, are presented in Table 3. These data were obtained from uniaxial tensile tests carried out on samples which were cut from the annealed copper sheet and aluminum sheet in the rolling direction. The average shear strength of a single-lap $\mathrm{Al} / \mathrm{Cu}$ bimetallic joint obtained during shear tests by tension loading was $68.9 \mathrm{MPa}$ at temperature $T=293 \mathrm{~K}$. Tests were carried out on specially prepared $\mathrm{Al} / \mathrm{Cu}$ specimens, based on the procedures of the ASTM D5656-01 standard (Ref 20). The scanning electron microscope (SEM) photograph of the connection area of aluminum and copper layers is shown in Fig. 2. The $\mathrm{Al} / \mathrm{Cu}$ bimetal interface in the fabricated sheet (initial state) is not smooth, and the $\mathrm{Al}$ and $\mathrm{Cu}$ layers are squeezed into each other by the rolling mill. For the as-rolled $\mathrm{Al} / \mathrm{Cu}$ sheet, no cracks and no intermetallic layer on the interface were observed.

In order to eliminate the asymmetry of the "dog-bone" $\mathrm{Al} /$ $\mathrm{Cu}$ specimen's shape relative to the axis of tensile load, resulting from the removal of part of the copper layer, metal plates of a thickness equal to the thickness of the copper layer that was cut out were glued onto the grip section of specimens. This procedure minimized the potential non-axiality of load applied to the specimen during tensile tests.

\subsection{Testing Procedure}

In order to obtain information about the mechanical properties of the tested material, uniaxial monotonic tensile tests were performed on flat specimens (Fig. 1a). Tests were performed accounting for the direction in which specimens were cut out from the sheet as well as the guidelines given in technical standards PN-EN ISO 6892-1:2010 (Ref 21) and ASTM E8/E8M-15 (Ref 22). Tensile tests were performed at a constant strain rate of $\dot{\varepsilon}=2 \times 10^{-3} 1 / \mathrm{s}$ and at a constant temperature of $293 \mathrm{~K}$. Measurement of specimen strain was taken using two extensometers, of which one was fastened over the specimen's gauge length $l_{\mathrm{o}}=50 \mathrm{~mm}$ and the other over its width $b=12.0 \mathrm{~mm}$. All tests were performed on the MTS 858 Mini Bionix testing machine. Based on the tests, basic elastoplastic properties of the tested materials were determined for the selected directions $\left(0^{\circ}, 90^{\circ}\right)$, i.e., elastic limit $R_{\mathrm{p} 0.05}$, yield point $R_{\mathrm{p} 0.2}$, tensile strength $R_{\mathrm{m}}$, Young's modulus $E$, maximum uniform plastic strain $\varepsilon_{u_{\max }}$ and hardening curve coefficients $n, K, \varepsilon_{0}$. In addition, the specific energy of uniform elastic strain $L_{\mathrm{e}}$ and plastic strain $L_{\mathrm{p}}$ as well as the Lankford coefficient (Ref 23) of normal anisotropy $r$ was determined. All of the above mechanical quantities were determined in the plane of the sheet. In the rolling direction, these quantities are designated by the index "RD"-rolling direction, and in the direction perpendicular to rolling, the index "TD" - transversal direction, was adopted.

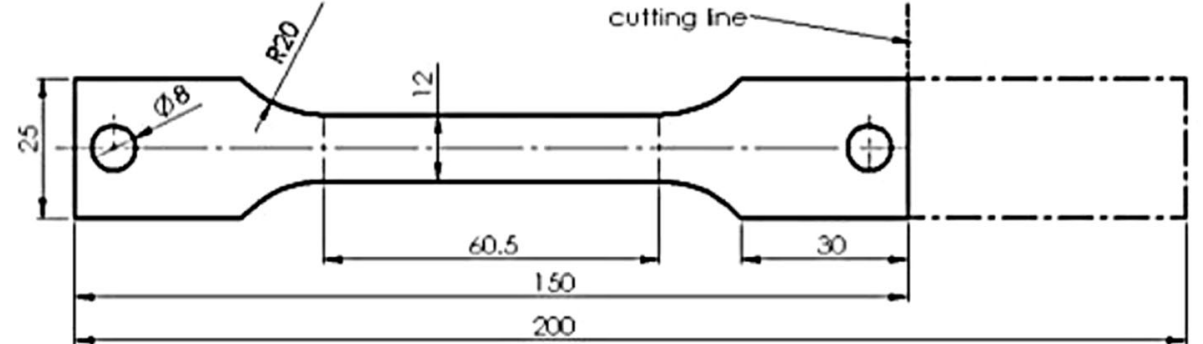

(a)

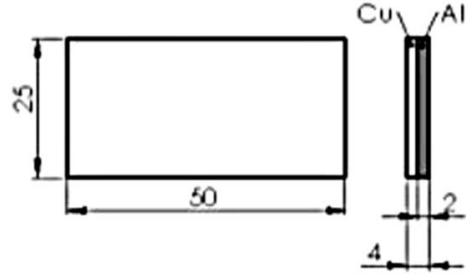

(b)

Fig. 1 Geometry of the specimens used in: (a) quasi-static tensile tests and (b) impulse excitation tests. The drawing shows the cutting line for specimen's separation 
Table 1 Chemical composition of the M1E copper layer

\begin{tabular}{lcccccrrr}
\hline $\mathbf{C u}+\mathbf{A g}$ & $\mathbf{F e}$ & Ni & Zn & Pb & Sn & As & P & Other \\
\hline$\%$ & & & & & & & \\
99.99 & 0.002 & 0.003 & 0.002 & 0.0005 & 0.001 & 0.0005 & 0.0005 \\
\hline
\end{tabular}

Table 2 Chemical composition of the A1 aluminum layer

\begin{tabular}{lllllllll}
\hline Al & Fe & Si & Cu & Mg & Mn & Ti & Zn & Other \\
\hline$\%$ & & & & & & & \\
99.72 & 0.15 & 0.11 & 0.002 & 0.002 & 0.003 & 0.003 & 0.005 & 0.005 \\
\hline
\end{tabular}

Table 3 Basic mechanical properties of $\mathrm{Al}$ sheet and $\mathrm{Cu}$ sheet in the initial state after annealing (recrystallizing) before joining (cold rolling)

\begin{tabular}{lcccrc}
\hline & \multicolumn{5}{c}{ Mechanical property } \\
\cline { 2 - 6 } & $\begin{array}{c}\boldsymbol{R}_{\mathbf{p 0 . 0 5}} \\
\mathbf{M P a}\end{array}$ & $\begin{array}{c}\boldsymbol{R}_{\mathbf{p 0 . 2}} \\
\mathbf{M P a}\end{array}$ & $\begin{array}{c}\boldsymbol{R}_{\mathbf{m}} \\
\mathbf{M P a}\end{array}$ & $\begin{array}{c}\boldsymbol{E} \\
\mathbf{G P a}\end{array}$ & $\begin{array}{c}\boldsymbol{A}_{\mathbf{5 . 6 5}} \\
\%\end{array}$ \\
\hline Al sheet $\left(0^{\circ}\right)$ & 25.9 & 29.1 & 72.8 & 66.3 & 39.0 \\
$\mathrm{Cu}$ sheet $\left(0^{\circ}\right)$ & 64.3 & 74.9 & 214.0 & 116.3 & 52.2 \\
$A_{5.65^{-}}$ultimate elongation & & & & \\
\hline
\end{tabular}

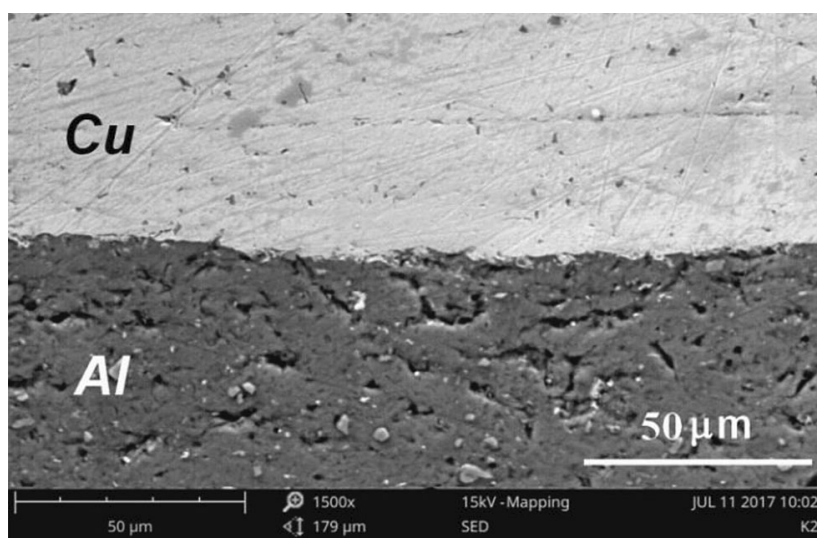

Fig. 2 SEM photograph of connection area of $\mathrm{Al}$ and $\mathrm{Cu}$ layers

Due to the nature of the starting material's shape $(\mathrm{Al} / \mathrm{Cu}$ sheet), certain elastic properties of the $\mathrm{Al} / \mathrm{Cu}$ sheet were determined using the dynamic method described in standard ASTM E1876-09 (Ref 24). This method applies an acoustic resonance frequency analyzer for specimens in the shape of rectangular prisms (Fig. 1b) also cut out in the rolling direction $\left(0^{\circ}\right)$ and transversal direction $\left(90^{\circ}\right)$. In this manner, directional Young's moduli $E$, Kirchhoff moduli (coefficients of transverse elasticity) $G$, basic resonance frequencies $\chi_{\mathrm{f}}, \chi_{\mathrm{t}}$ and internal friction parameters $Q^{-1}$ were determined. In this case, measurement of these quantities was taken in the direction perpendicular to the sheet's plane (along its thickness), and results were designated by the symbol "ND" - normal direction.

The dynamic method employs the phenomenon of acoustic resonance, i.e., the phenomenon of rapid growth of the specimen vibrations (of sound waves) when the frequency of external stimulus vibrations is nearly the same as the natural vibration frequency of the tested physical system. This phenomenon is simultaneously accompanied by attenuation based on reduction of the amplitude of free vibrations in a vibrating system due to energy dissipation. The dynamic method makes it possible to obtain both quantitative information about values of elastic moduli and qualitative information about the tested material's integrity (Ref 25, 26). In the studies of Song et al. (Ref 27), this material testing technique was successfully used to determine the elastic constants of the composite epoxy board. Information on the value of the elastic constant (Young's modulus) of a metal composite can also be obtained by using a classical ultrasonic immersion device (Ref 25).

The essence of measurements taken according to the resonance method was to induce a small mechanical pulse (impact of the pulser) and initiate a mechanical wave (vibrations) in the tested specimen. These vibrations had a frequency spectrum consistent with the resonance frequency of the tested material, which in turn depended on the material's elastic properties as well as on the specimen's geometry, weight or density. The resultant vibrations were registered by a transducer (microphone), which then transmitted to a computer in the form of an electric signal. Mathematical algorithms of the software analyzed the spectrum of vibrations and computed values of resonance frequencies and signal damping. The RFDA basic 1.1 measuring system from the IMCE Company, operating according to the principle of impulse excitation technique, was used in this test. Technical information concerning this measurement technique is given in a work by Roebben et al. (Ref 28, 29), and analysis of errors in this method is discussed in a paper by Raggio et al. (Ref 30$)$.

For specimens in the shape of a rectangular prism and measurements in flexural vibration mode, Young's modulus is calculated from the following dependency:

$E=0.9465 \cdot\left(\frac{m \chi_{\mathrm{f}}^{2}}{b}\right) \cdot\left(\frac{L^{3}}{t^{3}}\right) T_{1}$,

where $E$-Young's modulus, $m$-mass of specimen, $L, t$, $b$-length, thickness, width of specimen, respectively, $\chi_{\mathrm{f}}$ - fun- 
damental flexural resonant frequency of specimen, $T_{1}$ - correction factor for fundamental flexural mode to account for geometrical parameters of specimen (Ref 31).

When measurement in torsion vibration mode was applied, the dependency serving for the determination of the Kirchhoff modulus (shear modulus) is taken in the following form:

$G=\frac{4 \cdot L \cdot m \cdot \chi_{\mathrm{t}}}{b \cdot t}\left[\frac{B}{1+A}\right]$,

where $G$-shear modulus, $m$-mass of specimen, $L, t$, $b$-length, thickness, width of specimen, respectively, $\chi_{\mathrm{t}}$ - fundamental torsion resonant frequency of specimen, $B$-correction factor of calculation ( $\operatorname{Ref} 31), A$ - an empirical correction factor dependent on the width-to-thickness ratio of test specimen (Ref 31).

\section{Results and Discussion}

Engineering curves $\varepsilon-\sigma$ obtained from tensile tests served for determination of basic mechanical properties of the tested bimetallic structures. Examples of the tensile curves of aluminum and bimetallic $\mathrm{Al} / \mathrm{Cu}$ specimens for the rolling direction $\left(0^{\circ}\right)$, throughout the entire range of elastic-plastic strains, are presented in Fig. 3. In turn, Fig. 4 presents

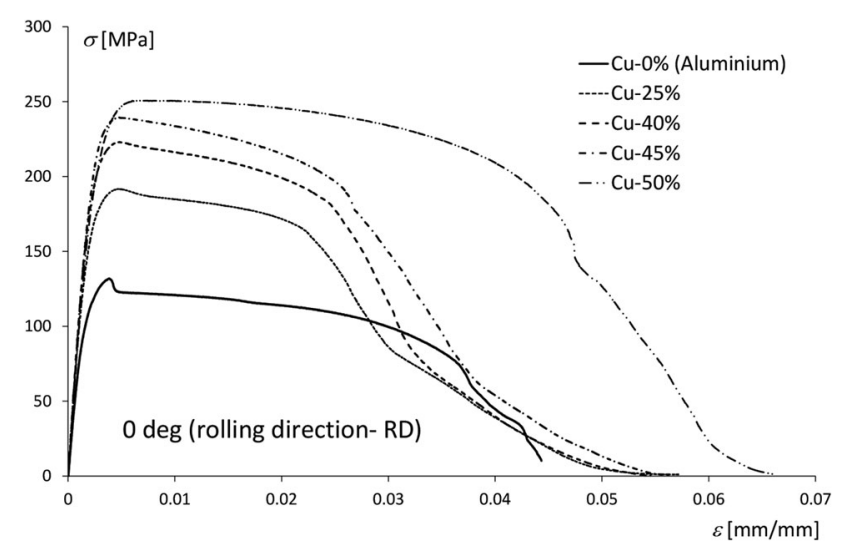

Fig. 3 Examples of engineering tensile curves for specimens cut in the rolling direction $\left(0^{\circ}\right)$

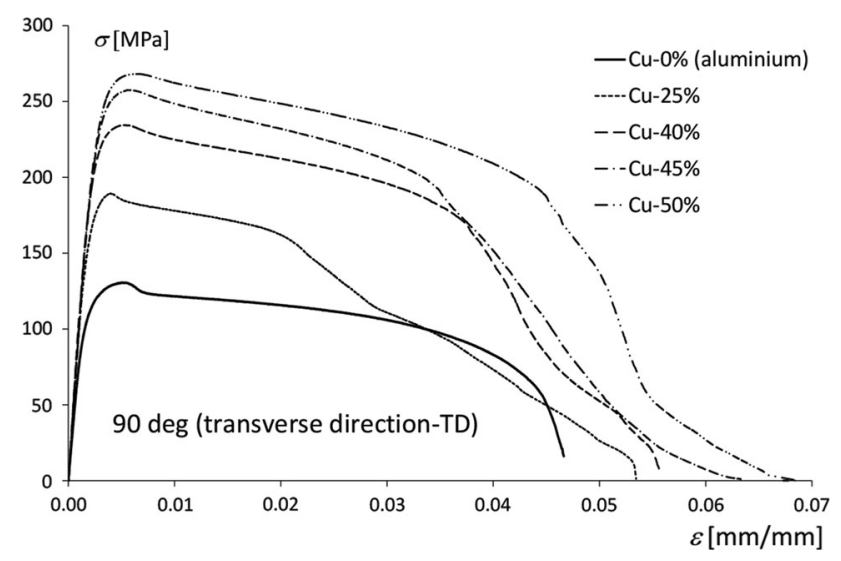

Fig. 4 Examples of engineering tensile curves for specimens cut in the transverse direction to the rolling direction $\left(90^{\circ}\right)$ analogous curves obtained for specimens cut in the direction perpendicular to the rolling direction $\left(90^{\circ}\right)$. Tensile charts contain information about copper $(\mathrm{Cu})$ content as a percentage in the $\mathrm{Al} / \mathrm{Cu}$ bimetal, with a symbolic designation assigned to each curve, i.e., $0 \%, 25 \%, 40 \%, 45 \%, 50 \%$.

Values of mechanical parameters obtained for bimetallic $\mathrm{Al} /$ $\mathrm{Cu}$ specimens (without a cut copper layer) and determined for three directions $\alpha=0^{\circ}, 45^{\circ}, 90^{\circ}$. relative to the rolling direction are given in Table 4 .

The shape and progression of tensile curves (Fig. 3 and 4) were slightly dependent on the direction of the specimen's cutting from the sheet. Aluminum (Al) specimens devoid of the copper layer and bimetallic $(\mathrm{Al} / \mathrm{Cu})$ specimens cut in the $\mathrm{RD}$ direction hardened slightly faster than those cut in the TD direction. The range of non-uniform strains constituted the majority of the entire elastic-plastic range in the case of all tested specimens. This indicates high strain anisotropy of aluminum and copper layers in the $\mathrm{Al} / \mathrm{Cu}$ bimetal in the sheet plane, which is due to the forming process (cold rolling), i.e., their integration into a single solid. The joining process of the $\mathrm{Al}$ and $\mathrm{Cu}$ sheets during cold rolling caused values of limit stresses $R_{\mathrm{p} 0.05}, R_{\mathrm{p} 0.2}, R_{\mathrm{m}}$ obtained for the bimetal to be significantly higher than analogous values obtained for annealed $\mathrm{Al}$ and $\mathrm{Cu}$ sheets, while ductility of the bimetal decreased several times (Tables 3, 4 and Fig. 3, 4).

\subsection{Directional Elastic Properties of Al/Cu Sheet}

The application of two methods for determining elasticity moduli made it possible to determine their values in three directions of the material's orthotropy. Figure 5 presents changes in the values of Young's moduli $E_{\mathrm{RD}}$ and $E_{\mathrm{TD}}$ in the plane of the $\mathrm{Al} / \mathrm{Cu}$ sheet, i.e., in the rolling direction and transversal direction, accordingly, accompanying the increasing share of the copper layer $\left(f_{\mathrm{Cu}}\right)$. Points corresponding to averaged moduli values $E_{\mathrm{RD}}$ and $E_{\mathrm{TD}}$, determined for aluminum specimens, were plotted on the $Y$ axis. It should be emphasized that these specimens were subjected to identical strain (technological) and heat processes to those performed on the $\mathrm{Al} / \mathrm{Cu}$ bimetal. The values of $E_{\mathrm{RD}}$ and $E_{\mathrm{TD}}$ grew nonlinearly as the share of copper in the $\mathrm{Al} / \mathrm{Cu}$ bimetal increased. Both charts have progressions of similar shape. Values of modulus $E_{\mathrm{TD}}$ for the TD direction grew up to a maximum (mean) value of approx. $112.9 \mathrm{GPa}$, and of modulus $E_{\mathrm{RD}}$ up to approx. $106.5 \mathrm{GPa}$, which corresponded to approx. $38-39 \%$ of the share of copper in the $\mathrm{Al} / \mathrm{Cu}$ bimetal. For $f_{\mathrm{Cu}}=38 \%, E_{\mathrm{TD}}$ values were greater than $E_{\mathrm{RD}}$ by approx. $7 \mathrm{GPa}$. Moduli $E_{\mathrm{TD}}, E_{\mathrm{RD}}$ decreased after reaching extreme values, while maintaining the same mutual difference. Therefore, it seems that the rule of mixtures according to Voigt (Ref 32) inaccurately estimates Young's modulus values for the $\mathrm{Al} / \mathrm{Cu}$ bimetal, as it is based solely on the elastic moduli values of the components and their volumetric shares in the bimetal. Voigt's formula does not account for the effect of technological processes on the $\mathrm{Al} / \mathrm{Cu}$ bimetal's structure at the stage of its formation. Aluminum specimens (bimetallic specimens devoid of the copper layer) had slightly greater values for the TD direction than for RD, which can be ascribed to different hardening processes of this material.

Figure 6(a) presents changes in the values of elasticity moduli $\left(E_{\mathrm{ND}}\right)$ of the $\mathrm{Al} / \mathrm{Cu}$ bimetal in the direction perpendicular to the plane of the $\mathrm{Al} / \mathrm{Cu}$ sheet. To measure them, the acoustic resonance method described earlier was applied in 


\begin{tabular}{|c|c|c|c|c|c|c|c|}
\hline \multirow[b]{2}{*}{$\begin{array}{l}\text { Angle of specimen cut with } \\
\text { respect to rolling direction } \alpha,{ }^{\circ}\end{array}$} & \multicolumn{7}{|c|}{ Mechanical property } \\
\hline & $\begin{array}{l}R_{\mathrm{p} 0.05} \\
\mathrm{MPa}\end{array}$ & $\begin{array}{l}R_{\mathrm{p} 0.2} \\
\mathrm{MPa}\end{array}$ & $\begin{array}{r}R_{\mathrm{m}} \\
\mathrm{MPa}\end{array}$ & $\begin{array}{c}E \\
\text { GPa }\end{array}$ & $\underset{\mathrm{MJ} / \mathbf{m}^{3}}{L_{\mathrm{p}}}$ & $\begin{array}{c}L_{\mathrm{e}} \\
\mathbf{M J} / \mathbf{m}^{3}\end{array}$ & $\begin{array}{c}\varepsilon_{\boldsymbol{u}_{\max }} \\
\ldots\end{array}$ \\
\hline 0 & 190.7 & 239.3 & 249.6 & 96.3 & 3.76 & 0.33 & 0.010 \\
\hline 45 & 177.1 & 234.8 & 247.6 & 84.2 & 4.34 & 0.36 & 0.008 \\
\hline 90 & 221.5 & 263.4 & 267.9 & 103.1 & 3.72 & 0.35 & 0.007 \\
\hline
\end{tabular}

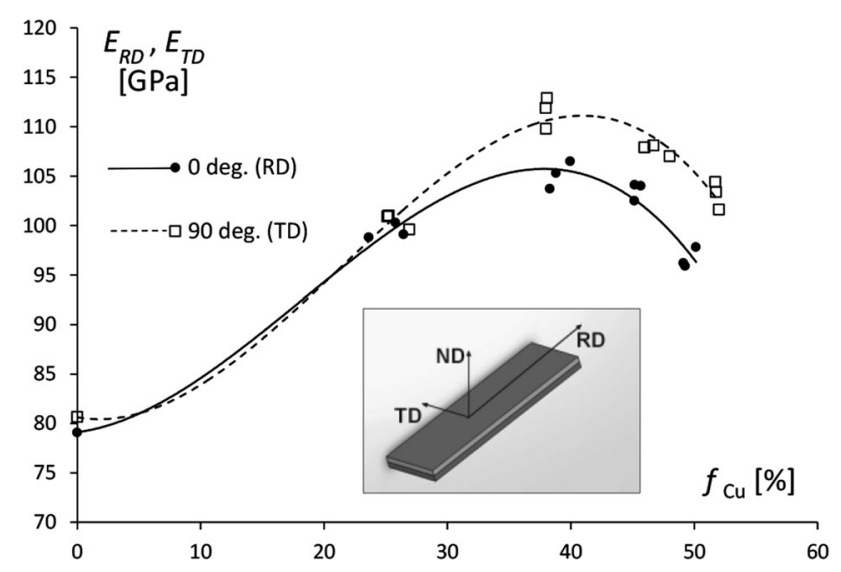

Fig. 5 Effect of increase in the percentage fraction copper in the $\mathrm{Al} / \mathrm{Cu}$ bimetal on values of elastic moduli $E_{\mathrm{RD}}$ and $E_{\mathrm{TD}}$

flexural mode. Similarly as in the case of moduli $E_{\mathrm{RD}}$ and $E_{\mathrm{TD}}$ obtained from tensile tests, a nonlinear increase in the values of moduli $E_{\mathrm{ND}}$ is also observed here as $f_{\mathrm{Cu}}$ increases. This takes place in specimens cut in both TD and RD directions. Differences in the values of moduli for both compared directions are decidedly lower than in the case of $E_{\mathrm{RD}}$ and $E_{\mathrm{TD}}$.

In the case of modulus of transverse elasticity $G_{\mathrm{ND}}$ (Fig. 6b), where the acoustic resonance method was also applied in torsion mode, no significant differences in its values resulting from the choice of direction of cutting specimens from the sheet's plane were observed. On both charts (Fig. 6a, b), during the growth of the $f_{\mathrm{Cu}}$ value within the $25-50 \%$ range, a slight, nearly linear increase in the values of moduli $E_{\mathrm{ND}}$ and $G_{\mathrm{ND}}$ is observed.

Figure 7 illustrates changes of resonance frequencies accompanying the growth of $f_{\mathrm{Cu}}$, registered during the determination of moduli $E_{\mathrm{ND}}, G_{\mathrm{ND}}$. For the tested $f_{\mathrm{Cu}}$ values, greater resonance frequency values were obtained for bending than for torsion. The shape of the progressions of $\chi_{\mathrm{f}}=F\left(f_{\mathrm{Cu}}\right)$ and $\chi_{\mathrm{t}}=$ $F\left(f_{\mathrm{Cu}}\right)$ were similar in both cases.

Another very important parameter that can be obtained from measurements employing the impulse excitation technique is internal friction $Q^{-1}$. It is defined by the following dependency:

$Q^{-1}=\frac{\Delta W}{2 \pi W}$

where $\Delta W$-energy dissipated per unit volume over one cycle, $W$ - energy stored per unit volume.

In the applied method, the subjects of measurement were resonance frequencies $\chi_{\mathrm{f}}, \chi_{\mathrm{t}}$, which were assigned to vibrations corresponding to the equation:

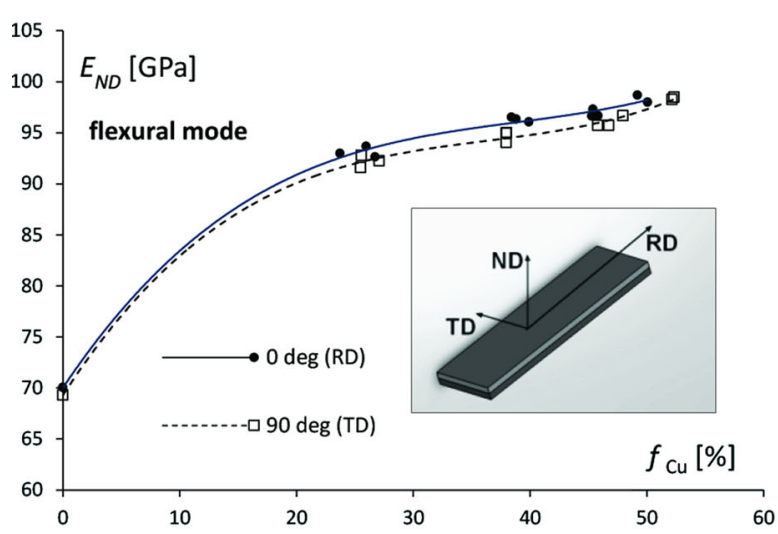

(a)

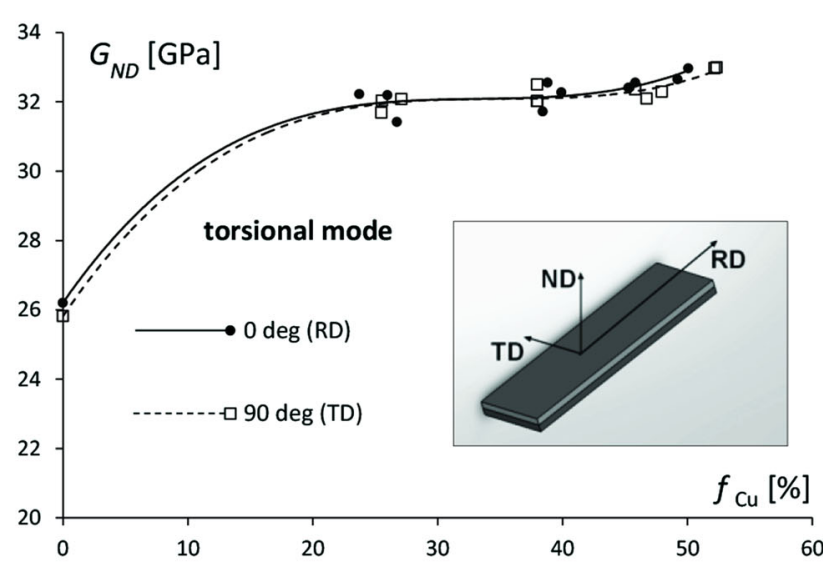

(b)

Fig. 6 Influence of the percentage fraction of copper in the $\mathrm{Al} / \mathrm{Cu}$ bimetal on the values of elastic modulus $E_{\mathrm{ND}}$ (a) and modulus $G_{\mathrm{ND}}$ (b), which were determined in the perpendicular direction to the plane of sheet $\mathrm{Al} / \mathrm{Cu}$

$x(t)=A e^{-k t} \sin \left(2 \pi \chi_{\mathrm{f}(\mathrm{t})} t+\varphi\right)$,

where $A, \varphi, k$-parameters of Eq $4, \chi_{\mathrm{f}(\mathrm{t})}$-fundamental flexural and torsional resonance frequency, $t$ - time parameter.

Internal friction is determined by means of Fourier analysis and calculated using the formula:

$Q^{-1}=\frac{k}{\pi \chi_{\mathrm{f}(\mathrm{t})}}$.

Figure 8 presents the change of internal friction $Q^{-1}$ occurring alongside the growth of the thickness of the copper 


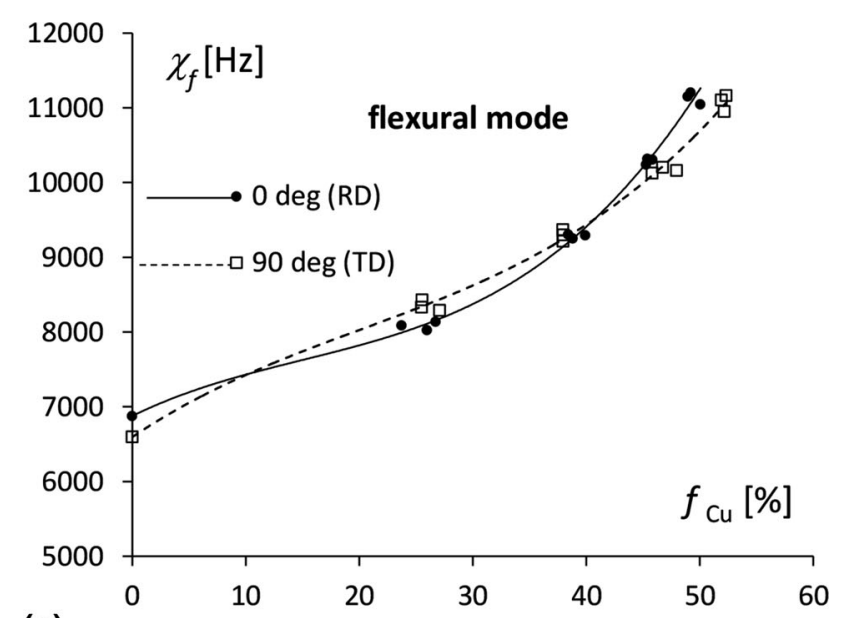

(a)

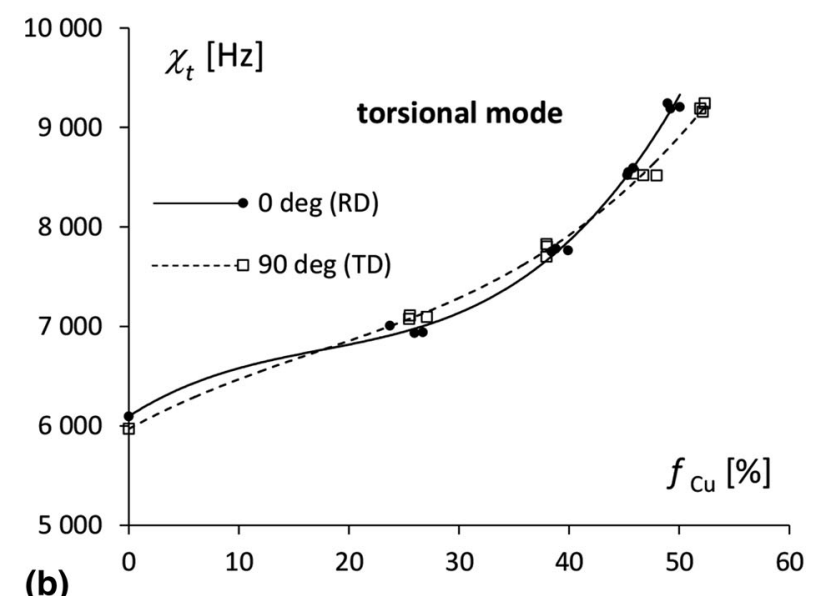

Fig. 7 Variation of the resonance frequencies of the acoustic signals accompanying the increase in the percentage fraction copper in the $\mathrm{Al} / \mathrm{Cu}$ bimetal, which was recorded in the flexural mode (a) and torsional mode (b)

layer in the $\mathrm{Al} / \mathrm{Cu}$ bimetal. This parameter was measured in flexural (Fig. 8a) and torsional (Fig. 8b) modes. In both cases, dependencies were strongly nonlinear and differentiate $Q^{-1}$ values measured for the RD and TD directions. In the case of registration of $Q^{-1}$ in flexural mode, as $f_{\mathrm{Cu}}$ increases, the value of this quantity drops from $5.6 \times 10^{-4}$ to $3.6 \times 10^{-4}$ for RD specimens and from $4.7 \times 10^{-4}$ to $3.9 \times 10^{-4}$ for TD specimens. In flexural mode, despite their lesser thickness, aluminum specimens exhibited a greater value of internal friction $Q^{-1}$ than bimetallic specimens did, and TD specimens displayed a greater value of this parameter than RD specimens did. Nonlinear reduction of $Q^{-1}$ alongside the growth of $f_{\mathrm{Cu}}$ can be ascribed to changes in the bimetal's internal structure induced by the increasing thickness of the copper layer, which is characterized by lesser internal friction than that of aluminum. Besides this, the rolling process resulted in greater hardening of $\mathrm{TD} \mathrm{Al} / \mathrm{Cu}$ specimens, which had a more plasticized structure (texture) and attenuated generated vibrations more strongly.

In torsional mode, curves of $Q^{-1}=F\left(f_{\mathrm{Cu}}\right)$ variation exhibited minimums for $f_{\mathrm{Cu}}=40 \%$, and $Q^{-1}$ values were similar for the RD and TD directions. Selection of the proper mode of measurement (flexural or torsional) determined the range of (a)

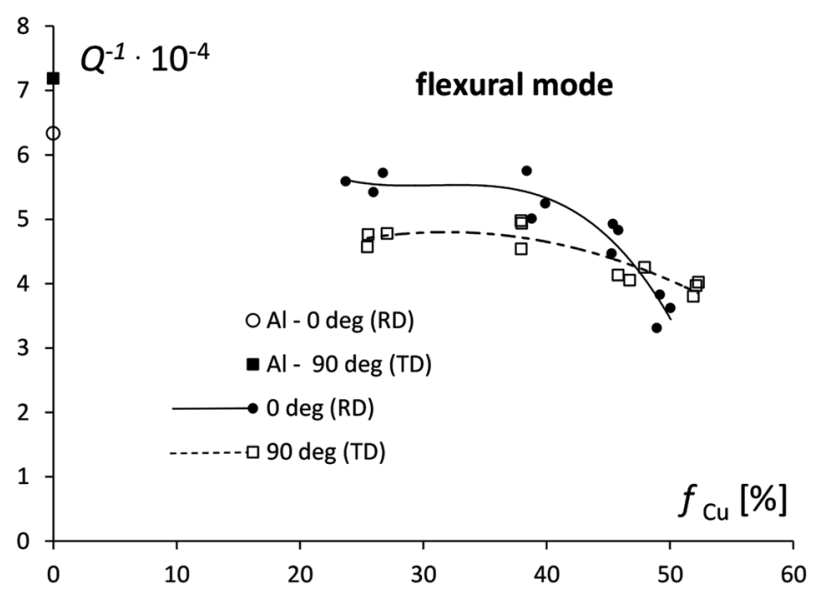

(b)

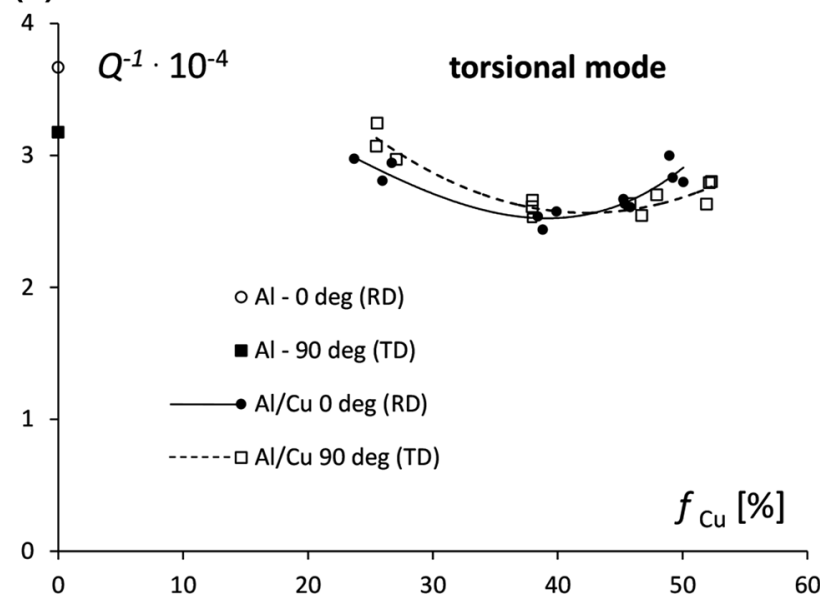

Fig. 8 Variability of internal friction $Q^{-1}$ during the increase in the percentage fraction of copper in $\mathrm{Al} / \mathrm{Cu}$ bimetal, which was recorded in the flexural mode (a) and torsional mode (b)

$Q^{-1}$ values, which was characterized by greater values in the case of bending than in the case of torsion.

Increasing thickness of the copper layer in the bimetal caused nonlinear growth of the unit energy of elastic strain $L_{\mathrm{e}}$, which was characterized by greater values for TD compared to $\mathrm{RD}$ (Fig. 9). As $f_{\mathrm{Cu}}$ grew, the difference in $L_{\mathrm{e}}$ value also increased between $\mathrm{RD}$ and $\mathrm{TD}$ specimens, amounting to $0.02 \mathrm{MJ} / \mathrm{m}^{3}$ for $f_{\mathrm{Cu}}=50 \%$.

\subsection{Directional Plastic Properties of Materials}

Changes in unit specific energy of uniform plastic strain $L_{\mathrm{p}}$ of RD and TD specimens depending on the share of copper in the $\mathrm{Al} / \mathrm{Cu}$ bimetal, as a percentage, are presented in Fig. 10. It was observed that, as the $f_{\mathrm{Cu}}$ parameter increases, $L_{\mathrm{p}}$ grows nonlinearly for both $\mathrm{RD}$ and $\mathrm{TD}$ specimens. For similar $f_{\mathrm{Cu}}$ values, the energy expenditure $L_{\mathrm{p}}$ required for plastic deformation of a unit of the $\mathrm{Al} / \mathrm{Cu}$ bimetal's volume was greater for $\mathrm{RD}$ than for TD. The process of axial tension of specimens within the plastic strain range (Fig. 10) has an energy demand for deformation of a unit of the tested materials' volume one order of magnitude greater than within the elastic range (Fig. 9). 


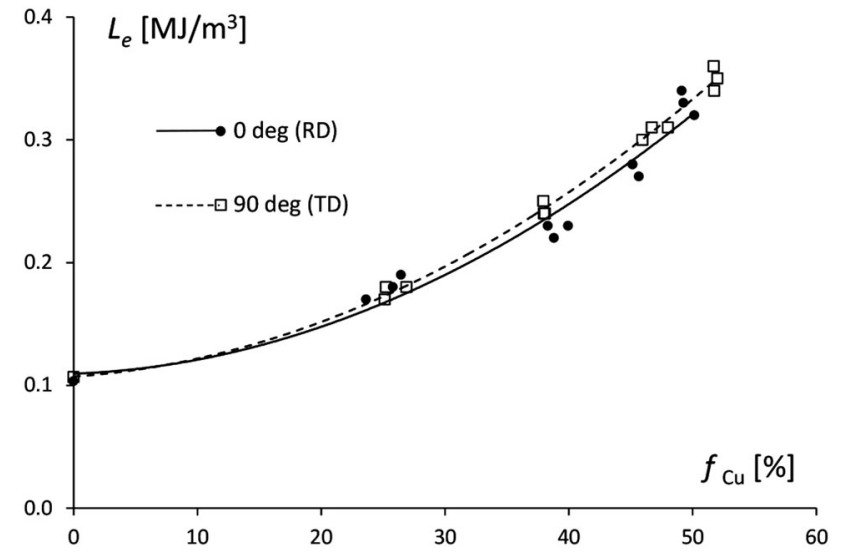

Fig. 9 Variation of elastic strain energy per unit volume $L_{\mathrm{e}}$ with the increase in percentage content of copper in $\mathrm{Al} / \mathrm{Cu}$ bimetal volume

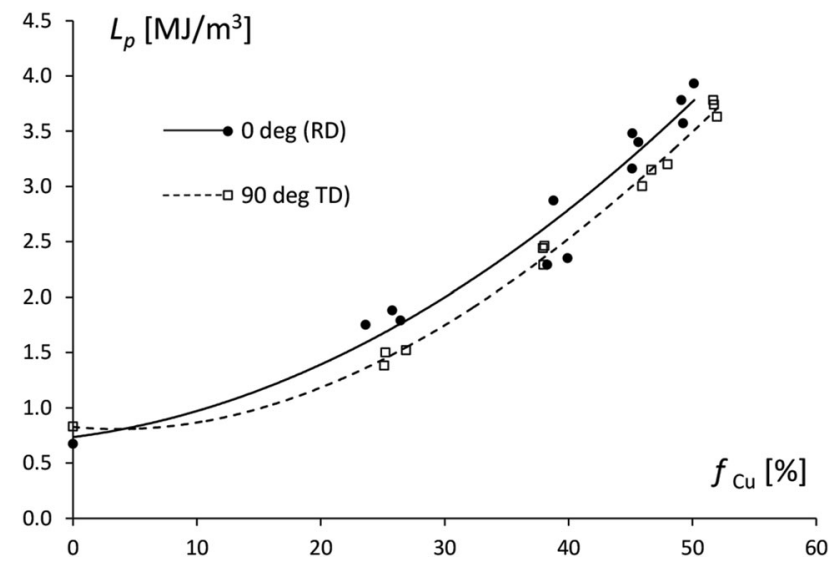

Fig. 10 Variation of the uniform strain energy per unit volume $L_{\mathrm{p}}$ of specimens for RD and TR directions with the increase in the percentage content of the copper in bimetal $\mathrm{Al} / \mathrm{Cu}$

Limit stress values $R_{\mathrm{p} 0.05}$ and $R_{\mathrm{p} 0.2}$ required to induce permanent deformation (plastic strain), 0.05 and $0.2 \%$, respectively (Fig. 11a, b), took on a linear configuration as copper content grew in $\mathrm{Al} / \mathrm{Cu}$. However, the values of these stresses obtained in tests on TD specimens were greater than analogous values for RD specimens as the value of $f_{\mathrm{Cu}}$ increased. Similar dependencies were observed for ultimate tensile strength $R_{\mathrm{m}}$ and TD and RD specimens for which the goodness of fit of regression lines to experimental data was significantly better than for $R_{\mathrm{p} 0.05}=F\left(f_{\mathrm{Cu}}\right)$. In their paper (Ref 18), Lee and Kim observed similar dependencies between yield point $R_{\mathrm{p} 0.2}$ as well as tensile strength $R_{\mathrm{m}}$ and the growing share of one of the components in the aluminum-stainless steel bimetal. They demonstrated the suitability of the law of mixtures for estimating $R_{\mathrm{p} 0.2}$ and $R_{\mathrm{m}}$ based on limit stress values obtained in tests for the components and their volumetric shares in the composite.

Based on the progression of the dependencies shown in Fig. 11 and 12, it can be stated that the differences between $R_{\mathrm{p} 0.05}, R_{\mathrm{p} 0.2}$ and $R_{\mathrm{m}}$ for $\mathrm{RD}$ and TD increased as copper content increased in the $\mathrm{Al} / \mathrm{Cu}$ bimetal, reaching values of $25.6 \mathrm{MPa}$, 17.1 $\mathrm{MPa}$ and 14.2 $\mathrm{MPa}$, accordingly, for $f_{\mathrm{Cu}}=50 \%$. (a)

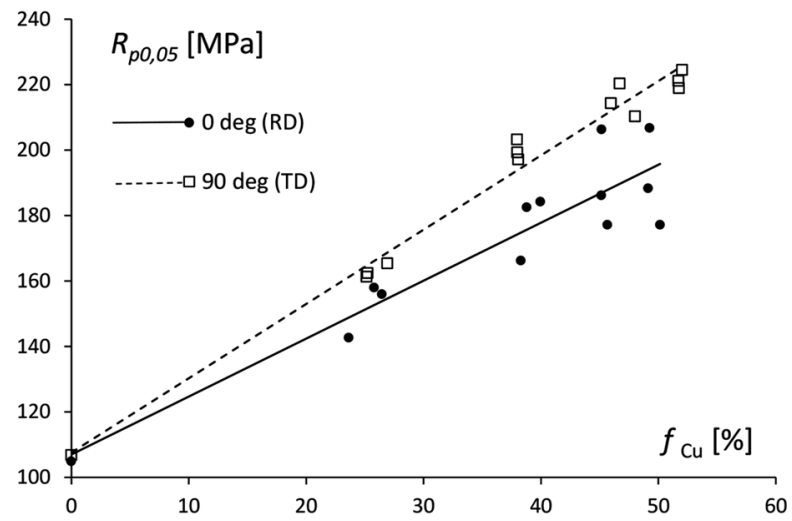

(b)

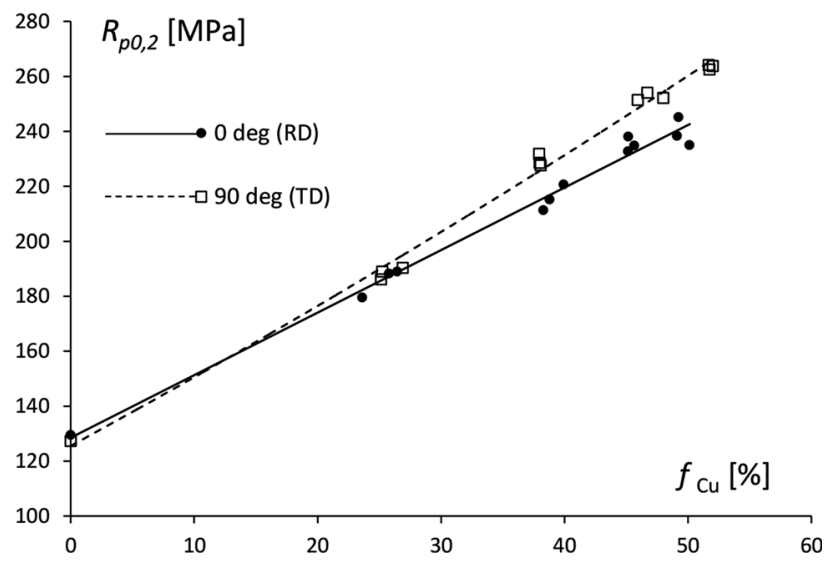

Fig. 11 Variation of the elastic limit $R_{\mathrm{p} 0.05}$ (a) and yield strength $R_{\mathrm{p} 0.2}$ (b) values corresponding to permanent deformation of 0.05 and $0.2 \%$ with increasing copper content in the $\mathrm{Al} / \mathrm{Cu}$

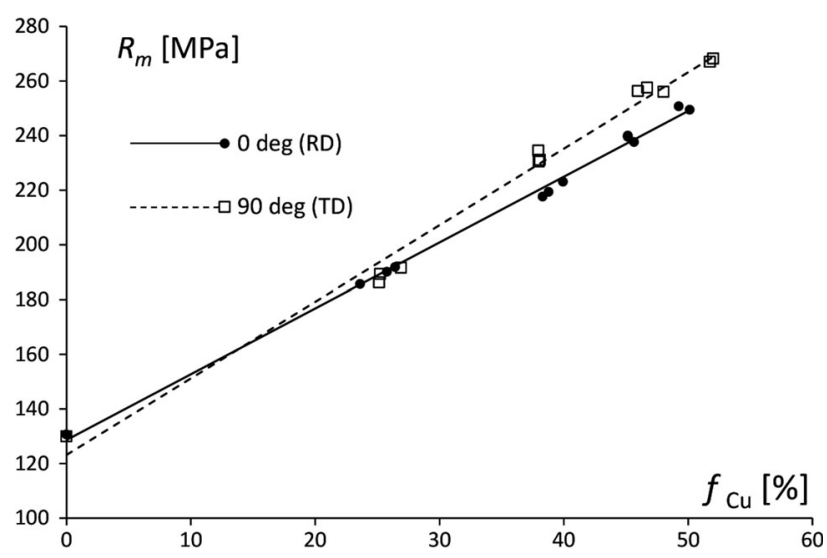

Fig. 12 Variability of the tensile strength values $R_{\mathrm{m}}$ with increasing copper content in the $\mathrm{Al} / \mathrm{Cu}$

The hardening process taking place during tension has a strong effect on relationships between limit values of stresses $R_{\mathrm{p} 0.05}, R_{\mathrm{p} 0.2}, R_{\mathrm{m}}$, and increasing copper content in $\mathrm{Al} / \mathrm{Cu}$. Swift's three-parameter equation (Ref 33) in the form below was applied to observe the hardening process of the $\mathrm{Al} / \mathrm{Cu}$ bimetal and aluminum over the course of quasi-static, monotonic tension: 
$\sigma_{t}=K\left(\varepsilon_{\mathrm{o}}+\varepsilon_{\mathrm{t}}\right)^{n}$

where $\sigma_{\mathrm{t}}, \varepsilon_{\mathrm{t}}$-true stress and true strain, respectively, $K, n, \varepsilon_{0}$ - coefficients of Eq 6 .

This equation was successfully applied to describe hardening of aluminum-steel sheet in a work by Parsa et al. (Ref 34).

Coefficients $K, n$ and $\varepsilon_{\mathrm{o}}$ from Eq 6 characterized the degree of strain hardening of the $\mathrm{Al} / \mathrm{Cu}$ bimetal and aluminum. Hardening was the effect of the plastic (technological) strains during production of the bimetal $\mathrm{Al} / \mathrm{Cu}$, i.e., strains occurring in the $\mathrm{Al}$ and $\mathrm{Cu}$ layers in the joining process and also during tensile tests. Values of coefficients $K, n$ and $\varepsilon_{0}$ obtained for aluminum and the as-delivered $\mathrm{Al} / \mathrm{Cu}$ bimetal are presented in Table 5. Changes in the values of hardening coefficients $n$ and $K$ resulting from the increasing thickness of the copper layer for $\mathrm{RD}$ and TD are presented in Fig. 13. Within the range of tested $f_{\mathrm{Cu}}$, the mean value of the hardening coefficient $n$ for the RD $\mathrm{Al} / \mathrm{Cu}$ bimetal was greater by 0.032 than for $\mathrm{TD}$, and of coefficient $K$ by $91 \mathrm{MPa}$. Similar relationships were present for aluminum (Al) in the tested TD and RD directions, for which differences with respect to $n$ and $K$ amounted to 0.03 and $90 \mathrm{MPa}$, respectively. A slight drop in the value of the hardening coefficient $n$ is observed for both aluminum and the bimetal as the thickness of the copper layer grows. The second coefficient, $K$, in Eq 6 is the equivalent of yield stress corresponding to uniform strain equal to one (Ref 16). As the thickness of the copper layer increases, values of this coefficient for TD grew linearly, with $K$ values for aluminum serving as the point of reference (Fig. 13b). In the work by Lee and Kim previously cited (Ref 18), linear growth of the coefficient $K$ was also noted as the share of one of the components within the volume of the stainless steel-aluminum bimetal was increased. To describe the bimetal's hardening, the authors applied the two-parameter Hollomon equation in the form of $\sigma_{\mathrm{t}}=K\left(\varepsilon_{\mathrm{t}}\right)^{n}$. In the case of RD (Fig. 13b), growth of the value of the coefficient $K$ was strongly nonlinear. It should be noted that, for RD specimens, the scatter of $K, n$ values was high compared to analogous values of these coefficients in the case of TD.

The plastic process (cold rolling) during joining of aluminum and copper layers introduced preliminary anisotropy, and further deformation of the $\mathrm{Al} / \mathrm{Cu}$ bimetallic sheet during the tensile test generated additional strain anisotropy. One parameter that makes it possible to assess the deformability of metal and determine the level of normal anisotropy is the Lankford coefficient $r$ (Ref 23). It was determined based on standard ASTM E517-00 (Ref 35). A review of publications concerning measurement of this coefficient $r$ can be found in the introduction to a work by Ramos et al. (Ref 36), which describes the results of experimental tests and simulations conducted on monolithic, low-carbon steel with the application of this coefficient. In their paper, Savoie et al. (Ref 37) described the relationships present between the texture and values of coefficient $r$ determined for aluminum sheet. With respect to bimetals, values of the anisotropy coefficient were analyzed by Lee and Kim (Ref 16) for stainless steel-aluminum as well as by Sun et al. (Ref 38) for aluminum-copper composite after pre-deformation.

For the tested materials, the $r$ coefficient was determined by measuring actual longitudinal and transverse dimensions of the specimen during tensile tests. This coefficient is defined as follows:

$r=\frac{\ln \frac{b}{b_{\mathrm{o}}}}{\ln \frac{t}{t_{\mathrm{o}}}}$,

where $b, b_{0}$-current and initial width of the specimen, respectively, $t, t_{0}$ - current and initial thickness of the specimen, respectively.

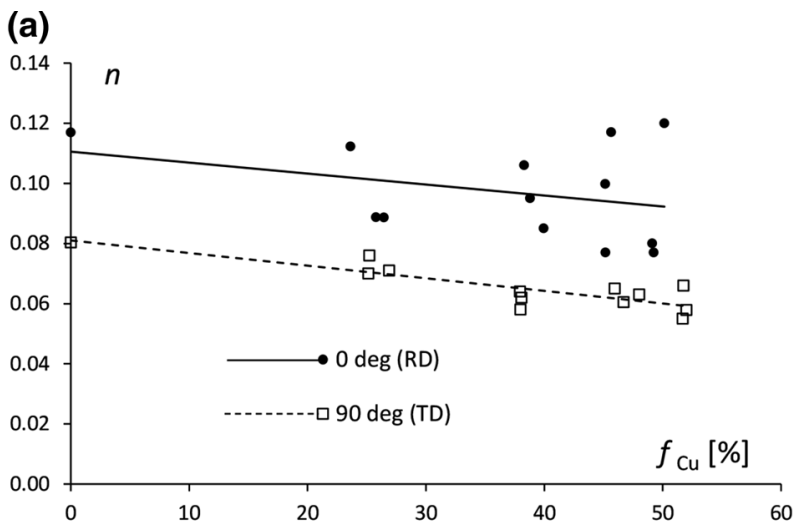

(b)

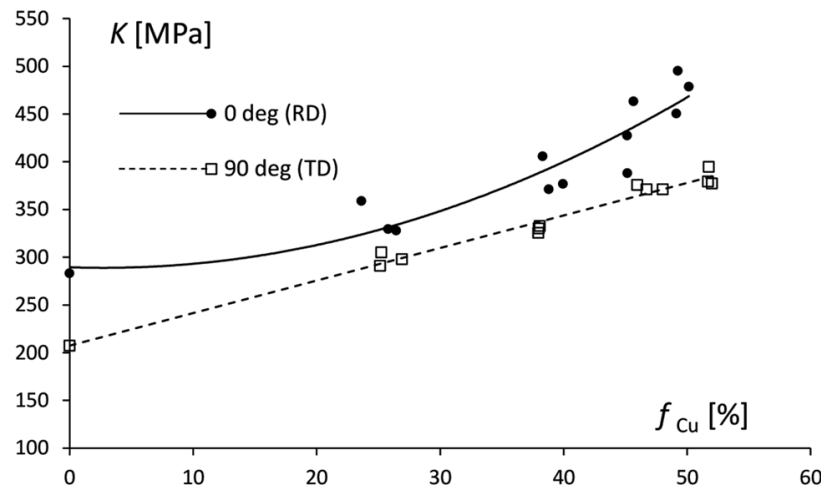

Fig. 13 Variation of coefficient values of Eq 6 with the increase in the copper content in $\mathrm{Al} / \mathrm{Cu}$ bimetal: (a) hardening coefficient $n$ and (b) coefficient $K$

Table 5 Average values of coefficients from Eq 6 obtained for the aluminum and $\mathrm{Al} / \mathrm{Cu}$ in the initial state $\left(f_{\mathrm{Cu}}=50 \%\right)$

\begin{tabular}{|c|c|c|c|c|c|c|}
\hline \multirow{2}{*}{$\begin{array}{l}\text { Angle of specimen cut with } \\
\text { respect to rolling direction } \alpha, \circ\end{array}$} & \multicolumn{2}{|c|}{$n$} & \multicolumn{2}{|c|}{ K (MPa) } & \multicolumn{2}{|c|}{$\varepsilon_{\mathbf{0}}$} \\
\hline & Al & $\mathbf{A l} / \mathbf{C u}$ & Al & $\mathbf{A l} / \mathbf{C u}$ & Al & $\mathbf{A l} / \mathbf{C u}$ \\
\hline 0 (RD) & 0.117 & 0.092 & 283.1 & 474.6 & -0.0014 & -0.0022 \\
\hline 90 (TD) & 0.080 & 0.060 & 207.3 & 383.6 & -0.0016 & -0.0026 \\
\hline
\end{tabular}




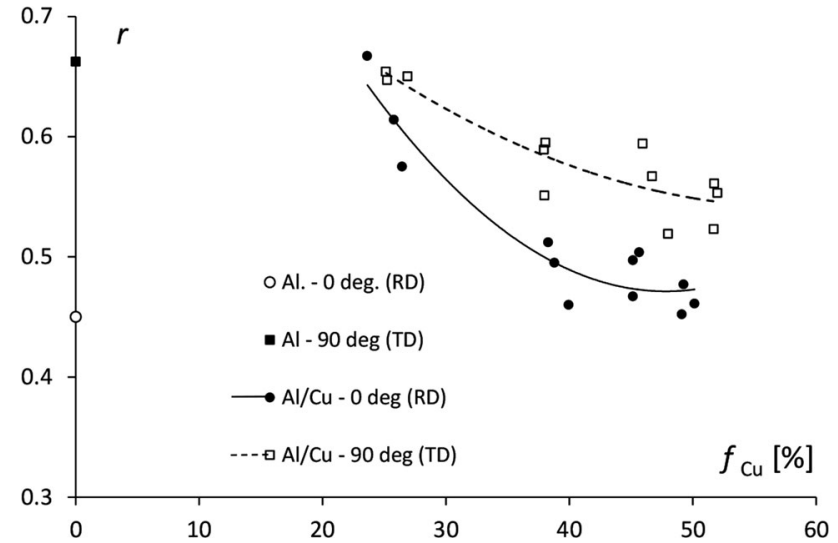

Fig. 14 Variation of values of the normal anisotropy coefficient $r$ corresponding to the increase in $f_{\mathrm{Cu}}$

Changes in the thickness of the tested specimens were small and could have generated large errors during measurement. To eliminate this inconvenience, the incompressibility condition was employed, as it is applicable to both copper and aluminum, which are incompressible materials. Thus, assuming that $l \cdot b \cdot t=l_{\mathrm{o}} \cdot b_{\mathrm{o}} \cdot t_{\mathrm{o}}=$ const., it can be written that:

$r=\frac{\ln \frac{b}{b_{\mathrm{o}}}}{\ln \frac{t}{t_{\mathrm{o}}}}=\frac{\ln \frac{b}{b_{\mathrm{o}}}}{\ln \frac{b l}{b_{\mathrm{o}} l_{\mathrm{o}}}}$,

where $l, l_{0}$-current and initial gauge length of the specimen, respectively.

The variability of the value of coefficient $r$ for aluminum and the $\mathrm{Al} / \mathrm{Cu}$ bimetal accompanying growth of parameter $f_{\mathrm{Cu}}$ is shown in Fig. 14. It pertains solely to true and plastic strains. Values of the coefficient $r$ were determined for the limit level of uniform (plastic) strain $\varepsilon=0.3 \%$. Values of the coefficient $r$ corresponding to aluminum are plotted on the $Y$ axis. For both $\mathrm{RD}$ and TD specimens, $r$ values decreased nonlinearly as copper content in the bimetal increased. However, the decrease in $r$ was more intensive in the case of RD specimens, for which high scatter of the value of coefficient $r$ occurred. It should be highlighted that, in the case of TD specimens, the mean value of coefficient $r$ for aluminum was similar to the value of this coefficient for the $\mathrm{Al} / \mathrm{Cu}$ bimetal with $25 \% \mathrm{Cu}$ content. Such relationships did not occur in the case of RD specimens where the coefficient $r$ for aluminum was at the level of the value for the $\mathrm{Al} / \mathrm{Cu}$ bimetal with approx. $50 \% \mathrm{Cu}$ content. The addition of the copper layer to aluminum significantly reduced the value of $r$ from 0.6 to 0.45 for RD and from 0.65 to 0.55 for TD. As a result, the ductility of bimetal was reduced, as well as its ability to deform during plastic forming, which may cause local reduction of the bimetal sheet thickness.

\section{Conclusions}

1. The elastoplastic properties of $\mathrm{Al} / \mathrm{Cu}$ bimetallic specimens characterized by different percentage fraction of components were strongly dependent on the direction of rolling the $\mathrm{Al} / \mathrm{Cu}$ sheet.

2. The law of mixtures incorrectly characterized the elastic constants of $\mathrm{Al} / \mathrm{Cu}$ bimetallic structures in the tested range of percentage shares of components in composite.
3. The impulse excitation technique together with the quasistatic tensile tests allowed to determine the values of the Young's modulus in the directions of orthotropy.

4. It was established that when the copper content in the $\mathrm{Al} / \mathrm{Cu}$ bimetallic structure increases, the Lankford ratio (normal anisotropy coefficient) and the internal friction nonlinearly decrease.

\section{Acknowledgments}

The paper was prepared as a part of the research Project No. S/ WM/4/2017 of Bialystok University of Technology financed by the Polish Ministry of Science and Higher Education.

\section{Open Access}

This article is distributed under the terms of the Creative Commons Attribution 4.0 International License (http://creativecommons.org/ licenses/by/4.0/), which permits unrestricted use, distribution, and reproduction in any medium, provided you give appropriate credit to the original author(s) and the source, provide a link to the Creative Commons license, and indicate if changes were made.

\section{References}

1. J.A. Forster, S. Jha, and A. Amatruda, The Processing and Evaluation of Clad Metals, JOM, 1993, 45(6), p 35-38

2. L. Smith and M. Celant, CASTI, Handbook of Cladding Technology, Casti Publishing Inc., Edmonton, 2000

3. I.-K. Kim and S.I. Hong, Mechanochemical Joining in Cold RollCladding of Tri-Layered $\mathrm{Cu} / \mathrm{Al} / \mathrm{Cu}$ Composite and the Interface Cracking Behavior, Mater. Des., 2014, 57, p 625-631

4. I.K. Kim and S.I. Hong, Effect of Heat Treatment on the Bending Behavior of Tri-Layered $\mathrm{Cu} / \mathrm{Al} / \mathrm{Cu}$ Composite Plates, Mater. Des., 2013, 47, p 590-598

5. L. Li, K. Nagai, and F. Yin, Progress in Cold Roll Bonding of Metals, Sci. Technol. Adv. Mater., 2008, 9(0230011), p 1-11

6. F. Findik, Recent Developments in Explosive Welding, Mater. Des., 2011, 32(3), p 1081-1093

7. X.L. Cheng, B.Z. Bai, Y.M. Gao, and C. Feng, Microstructural Characterization of the $\mathrm{Al} / \mathrm{Cu} / \mathrm{Steel}$ Diffusion Bonded Joint, Rare Met., 2009, 28(5), p 478-481

8. S.L. Semiatin and H.R. Piehler, Formability of Sandwich Sheet Materials in Plane Strain Compression and Rolling, Metall. Trans. A Phys. Metall. Mater. Sci., 1979, 10(1), p 97-107

9. C.W. Tan, Z.G. Jiang, L.Q. Li, Y.B. Chen, and X.Y. Chen, Microstructural Evolution and Mechanical Properties of Dissimilar Al-Cu Joints Produced by Friction Stir Welding, Mater. Des., 2013, 51, p 466-473

10. T. Sun, J. Liang, X. Guo, M. Ren, and L. Wang, Optical Measurement of Forming Limit and Formability of Cu/Al Clad Metals, J. Mater. Eng. Perform., 2015, 24(4), p 1426-1433

11. J.E. Lee, D.H. Bae, W.S. Chung, K.H. Kim, J.H. Lee, and Y.R. Cho, Effects of Annealing on the Mechanical and Interface Properties of Stainless Steel/Aluminum/Copper Clad-Metal Sheets, J. Mater. Process. Technol., 2007, 187, p 546-549

12. M. Acarer, Electrical, Corrosion, and Mechanical Properties of Aluminum-Copper Joints Produced by Explosive Welding, J. Mater. Eng. Perform., 2012, 21(11), p 2375-2379

13. L.Y. Sheng, F. Yang, T.F. Xi, C. Lai, and H.Q. Ye, Influence of Heat Treatment on Interface of $\mathrm{Cu} / \mathrm{Al}$ Bimetal Composite Fabricated by Cold Rolling, Compos. Part B Eng., 2011, 42(6), p 1468-1473

14. C. Yu, Z. Qi, H. Yu, C. Xu, and H. Xiao, Microstructural and Mechanical Properties of Hot Roll Bonded Titanium Alloy/Low Carbon Steel Plate, J. Mater. Eng. Perform., 2018, 27(4), p 1664-1672 
15. S.L. Semiatin and H.R. Piehler, Deformation of Sandwich Sheet Materials in Uniaxial Tension, Metall. Trans. A Phys. Metall. Mater. Sci., 1979, 10(1), p 85-96

16. D.N. Lee and Y.K. Kim, On the Rule of Mixtures for Flow Stresses in Stainless-Steel-Clad Aluminium Sandwich Sheet Metals, J. Mater. Sci., 1988, 23(2), p 558-564

17. D.N. Lee and Y.K. Kim, Tensile Properties of Stainless Steel-Clad Aluminium Sandwich Sheet Metals, J. Mater. Sci., 1988, 23(4), p 1436-1442

18. S.-H. Choi, K.-H. Kim, K.H. Oh, and D.N. Lee, Tensile Deformation Behavior of Stainless Steel Clad Aluminum Bilayer Sheet, Mater. Sci. Eng. A, 1997, 222(2), p 158-165

19. R. Uścinowicz, Processes of Deformation of Metal Layered Composites, Publishing House of the Bialystok University of Technology, Bialystok, 2015 (in Polish)

20. S.T. Results, D5656-10 Standard Test Method for Thick-Adherend Metal Lap-Shear Joints for Determination of the Stress-Strain Behavior of Adhesives in Shear By, 2013, 15(2000), p 1-8

21. Metale-Próba Rozciągania-Czéść 1: Metoda Badania w Temperaturze Pokojowej, PN-EN ISO 6892-1:2010, PKN, 2010, p 69 (in Polish)

22. Standard Test Methods for Tension Testing of Metallic Materials, ASTM E8/E8M-09, ASTM International, 2009, p 27

23. J.A. Lankford, W.T. Snyder, and S.C. Bausher, New Criteria for Predicting the Press Performance of Deep Drawing Sheets, Trans. ASM, 1950, 42, p 1197-1205

24. Standard Test Method for Dynamic Young's Modulus, Shear Modulus, and Poisson's Ratio by Impulse Excitation of Vibration, ASTM E187609, ASTM International, p 16, 2009

25. A. Mouchtachi, R. El Guerjouma, J.C. Baboux, P. Santini, P. Merle, and D. Bouami, Ultrasonic Study of Elastic Anisotropy of Material Composite, Appl. Compos. Mater., 2004, 11(6), p 341-351

26. A. Raman, S. Ibekwe, and T. Gabb, Impulse Excitation Study of Elasticity of Different Precipitated Microstructures in IN738LC at High Temperatures, J. Mater. Eng. Perform., 2005, 14(2), p 188-193

27. W. Song, Y. Zhong, and J. Xiang, Mechanical Parameters Identification for Laminated Composites Based on the Impulse Excitation Technique, Compos. Struct., 2017, 162, p 255-260
28. G. Roebben, B. Bollen, A. Brebels, J. Van Humbeeck, and O. Van Der Biest, Impulse Excitation Apparatus to Measure Resonant Frequencies, Elastic Moduli, and Internal Friction at Room and High Temperature, Rev. Sci. Instrum., 1997, 68(12), p 4511-4515

29. G. Roebben, B. Basu, J. Vleugels, J. Van Humbeeck, and O. Van der Biest, Innovative Impulse Excitation Technique for High-Temperature Mechanical Spectroscopy, J. Alloys Compd., 2000, 310(1-2), p 284287

30. L.I. Raggio, J. Etcheverry, G. Sánchez, and N. Bonadeo, Error Analysis of the Impulse Excitation of Vibration Measurement of Acoustic Velocities in Steel Samples, Phys. Proc., 2010, 3(1), p 297-303

31. Manual RFDA Basic, Version 1.1, IMCE NV, Genk, IMCE N.V., 2014

32. W. Voigt, Lehrbruch Des Krystallphysik, Springer Fachmedien Wiesbaden $\mathrm{GmbH}$, Wiesbaden, 1966 (in German)

33. H.W. Swift, Plastic Instability Under Plane Stress, J. Mech. Phys. Solids, 1952, 1(1), p 1-18

34. M.H. Parsa, K. Yamaguchi, and N. Takakura, Redrawing Analysis of Aluminum-Stainless-Steel Laminated Sheet Using FEM Simulations and Experiments, Int. J. Mech. Sci., 2001, 43(10), p 2331-2347

35. Standard Test Method for Plastic Strain Ratio $r$ for Sheet Metal", ASTM E517-00(2010), ASTM International, 2010, p 8

36. G.C. Ramos, M. Stout, R.E. Bolmaro, J.W. Signorelli, and P. Turner, Study of a Drawing-Quality Sheet Steel. I: Stress/Strain Behaviors and Lankford Coefficients by Experiments and Micromechanical Simulations, Int. J. Solids Struct., 2010, 47(17), p 2285-2293

37. J. Savoie, J.J. Jonas, S.R. Macewen, and R. Perrin, Evolution of RValue During the Tensile Deformation of Aluminium, Textures Microstruct., 1995, 23(3), p 149-171

38. T. Sun, J. Liang, X. Guo, and L.G. Li, Tensile Anisotropy of $\mathrm{Cu} / \mathrm{Al}$ Clad Metals after Prestrain Using Digital Image Correlation, J. Mater. Eng. Perform., 2013, 22(12), p 3825-3833

Publisher's Note Springer Nature remains neutral with regard to jurisdictional claims in published maps and institutional affiliations. 